\title{
Article
}

\section{Using the Principles of BIO2010 to Develop an Introductory, Interdisciplinary Course for Biology Students}

\author{
Kelly E. Matthews, ${ }^{*}$ Peter Adams, ${ }^{\dagger}$ and Merrilyn Goos*
}

\author{
*Teaching and Educational Development Institute and ${ }^{\dagger}$ Faculty of Science, University of Queensland, \\ Brisbane, QLD, Australia
}

Submitted March 15, 2010; Revised May 20, 2010; Accepted June 2, 2010

Monitoring Editor: John Jungck

\begin{abstract}
Modern biological sciences require practitioners to have increasing levels of knowledge, competence, and skills in mathematics and programming. A recent review of the science curriculum at the University of Queensland, a large, research-intensive institution in Australia, resulted in the development of a more quantitatively rigorous undergraduate program. Inspired by the National Research Council's BIO2010 report, a new interdisciplinary first-year course (SCIE1000) was created, incorporating mathematics and computer programming in the context of modern science. In this study, the perceptions of biological science students enrolled in SCIE1000 in 2008 and 2009 are measured. Analysis indicates that, as a result of taking SCIE1000, biological science students gained a positive appreciation of the importance of mathematics in their discipline. However, the data revealed that SCIE1000 did not contribute positively to gains in appreciation for computing and only slightly influenced students' motivation to enroll in upper-level quantitative-based courses. Further comparisons between 2008 and 2009 demonstrated the positive effect of using genuine, real-world contexts to enhance student perceptions toward the relevance of mathematics. The results support the recommendation from BIO2010 that mathematics should be introduced to biology students in first-year courses using real-world examples, while challenging the benefits of introducing programming in first-year courses.
\end{abstract}

\section{INTRODUCTION}

BIO2010: Transforming Undergraduate Education for Future Research Biologists (National Research Council, 2003) was a timely and credible call to action on reforming undergraduate science education, and it also offered a "blueprint" for this change. The report particularly catalyzed international discussion and debate around the need for stronger interdisciplinary approaches and greater quantitative rigor in life science education, resulting in broad consensus that change is urgently required (Kennedy and Gentile, 2003; Steitz, 2003; Bialek and Botstein, 2004; Gross et al., 2004; May, 2004;

DOI: $10.1187 /$ cbe.10-03-0034

Address correspondence to: Kelly E. Matthews (k.matthews1@ uq.edu.au).

(C) 2010 K. E. Matthews et al. CBE-Life Sciences Education (C) 2010 The American Society for Cell Biology. This article is distributed by The American Society for Cell Biology under license from the author(s). It is available to the public under an AttributionNoncommercial-Share Alike 3.0 Unported Creative Commons License (http://creativecommons.org/licenses/by-nc-sa/3.0).
Slonczewski and Marusak, 2004). However, challenges arise as individual institutions attempt to translate the blueprint of BIO2010 into practice. This is not surprising because the report aimed to address complex, long-standing issues (Marsh and Anderson, 1989), and the authors openly acknowledged the complexity of the change they were advocating.

Typically, higher education institutions are built around strong, long-standing disciplinary units with well-established cultures (Becker and Trowler, 2001). The BIO2010 call to build stronger interdisciplinary curricula in the life sciences represents a profound break from the norm. Specifically, BIO2010 suggests that increasing the interdisciplinary connections of mathematics and biology is the mechanism to build greater quantitative rigor in the life sciences. The issue of "math-phobia" and "statistics-phobia" has been well-documented (Schoenfeld, 1985; Onwuegbuzie et al., 1997; Burns, 1998; Pan and Tang, 2005). Although science as a discipline is viewed as being more quantitative than humanities-based disciplines, biology has gained a reputation for being the "nonquantitative science option." Hence, the recommendations in BIO2010 present a range of challenges around strengthening mathematics and statistics in the context of biol- 
ogy, where students (and often faculty as well) hold negative beliefs and perceptions toward these quantitative disciplines (Metz, 2008; Matthews et al., 2009). Then, BIO2010 went a step further, calling for students to participate in a genuine programming experience, going beyond the use of "black box software." As an educational recommendation, this is substantially less well-researched. However, initial research on programming suggests student learning in this area is complex (Robins et al., 2003), which will be heightened by a context of interdisciplinary learning. To achieve the interdisciplinary, quantitative undergraduate biology curriculum recommended in BIO2010, significant changes on behalf of both faculty and students would be required.

Citing recent literature and research, BIO2010 recognized that life science students in particular often lack appropriate quantitative skills (mainly mathematical and computational) and that these students also often do not appreciate the nature, role, and relevance of quantitative disciplines in life sciences. Thus, BIO2010 articulated issues of performance and perception. It proposed a range of strategies for restructuring curricula and ideas for new courses, highlighting exemplar case studies. The report stressed the importance and need to introduce the interdisciplinary, quantitative nature of biology starting in first-year courses. Although the BIO2010 mathematics and computing group recognized the difference between students in the life sciences who would use these approaches versus those who would contribute to the development of new approaches (e.g., using a math modeling package vs. creating a new modeling package), they felt that all undergraduates in life science should appreciate the fundamental principles of modeling, programming and quantitative, mathematical approaches.

This article focuses on the development, implementation, and evaluation of a BIO2010-inspired quantitative, interdisciplinary first-year course that resulted from a recent science review at the University of Queensland (UQ). We developed and implemented this course based on the BIO2010 guidelines that students must:

1. Be introduced to the interdisciplinary connections of biology and mathematics starting in first-year courses;

2. Encounter genuine mathematical content (as opposed to lower-level content only, such as arithmetic or simple algebra), presented in relevant contexts; and

3. Participate in programming in a "real" computer language starting in first-year courses, going beyond the use of black box software packages.

\section{UQ Context}

UQ is a member of the research-intensive Group of Eight universities in Australia and achieves highly in research and teaching. Enrollments are $\approx 38,000$ students, drawn from $>100$ countries across both undergraduate and postgraduate programs, supported by approximately 2400 academic staff. It is ranked as one of the top three Australian universities in terms of research income. The Bachelor of Science (B.Sc.) is a large, generalist degree program, with $>3000$ undergraduate students. Applicants are required to have completed high school English and Mathematics (which includes the study of functions, sequences, and series; an introduction to calculus; and probability and statistics), along with either chemistry or physics. Full-time students can complete the B.Sc. in 3 yr, with an optional Honors year for students with a high grade point average.

A comprehensive 2006 review of the undergraduate science curriculum at UQ found similar issues to those articulated in BIO2010 (the review documentation is available at http:// espace.library.uq.edu.au/collection/UQ:152846). The majority of undergraduate science students were intending to complete a biology-related major, and few were enrolling in the recommended courses with a quantitative base. The pattern of student enrollment, combined with faculty experiences of teaching biology students, led to the consensus that a new, more quantitative and interdisciplinary curriculum was needed. When the review committees were introduced to BIO2010, the impact was profound. $\mathrm{BIO} 2010$ better articulated the concerns raised during the review process and also validated them, highlighting an international issue. The report offered direction with examples and suggestions for how we could address these issues in practice. Thus, BIO2010 has provided a major contribution to our curriculum philosophy, particularly driving changes around first-year courses.

BIO2010 offered a broad blueprint for change, but institutional context will determine how that blueprint is translated into local practice. Along with the three recommendations from BIO2010 stated above, the development, implementation, and evaluation of the revised curriculum also was framed within the institutional context, including the need to:

1. Educate students in the interdisciplinary nature of modern science (not just between mathematics and science, but also between a range of science disciplines);

2. Achieve academic "buy-in" from all science disciplines; and

3. Develop course content and activities that are relevant, accessible, and appealing to a broad range of science students, not just life science students.

The B.Sc. Review Committee required that comprehensive evaluation be conducted on the new curriculum, going well beyond the standard institutional requirements for course evaluation. A study to determine the impact of the new UQ B.Sc. curriculum has been developed and is currently being implemented. It includes a comparison of the attitudes, perceptions, and abilities (including performance on a quantitative assessment task) of graduating science students across the old and new curricula.

A key outcome of the curriculum review and renewal was the introduction of a new course called Theory and Practice in Science (SCIE1000); development, delivery, and evaluation of SCIE1000 is the basis for this article. Given the attention BIO2010 paid to changing biology student perceptions toward mathematics and programming, we decided to focus on perception indicators in this study as our primary source of evidence. One reason for this is that student beliefs and perceptions toward mathematics have been shown to impact strongly on performance outcomes (Schoenfeld, 1985; Burns, 1998); thus, perception data can be viewed as an indirect measurement of performance. Second, measuring student learning (performance) is complex and involves a plethora of variables and confounding factors. Third, we are interested in long-term gains associated with the entire undergraduate curriculum, as opposed to short-term performance gains associated with a single course. As part of our broader and ongoing evaluation strategy, we are examining 
long-term changes in perception and performance by gathering data from multiple sources over a 3-yr time frame.

\section{Research Questions}

BIO2010 proposed that curricula based on the report's recommendations would result in students gaining an increased appreciation of the role of mathematics and programming in biological science, hence (hopefully) leading to greater intentions to enroll in more quantitative-based courses. This article was shaped by the following research questions:

1. How do biology students perceive an interdisciplinary, first-year course developed in the spirit of BIO2010?

2. How does this course impact biology student' perceptions of mathematics and programming in the context of science?

3. Will this course motivate biology students to enroll in upper-level quantitative courses?

\section{METHODS}

The data presented here are from the first and second offerings of the new course, in 2008 and 2009, respectively. The course was highly recommended for all commencing science students, but this study focuses on biology majors taking the course, which represents more than half of the enrolled students (details are provided under Study Participants and Response Rates). Peter Adams coordinated course development and cotaught it in both years.

\section{Course Description}

SCIE1000 is a gateway course offered in the first semester of science-based bachelor's degrees at UQ, including the Bachelor of Science, Bachelor of Biotechnology, Bachelor of Biomedical Science, and Bachelor of Marine Science. It is a single-semester, introductory course that is highly recommended for all new science students, regardless of major. The course is interdisciplinary in nature, not only demonstrating the mathematical foundations that underpin a range of science disciplines but also highlighting links between different science disciplines. The course aims and objectives are listed in Table 1 . The course runs for 13 teaching weeks, with $3 \mathrm{~h}$ of lecture, $1 \mathrm{~h}$ of computer-based practical, and a 1-h tutorial per week. Lectures are held in groups of 200400 students, but computer practicals and tutorials are limited to 30 students to foster small-group interactions.

\section{Course Development}

In early 2007 , a cross-disciplinary committee of $\approx 20$ faculty was established to develop the course. Faculty worked together to identify science themes in which mathematics and computation are pivotal. BIO2010 was used heavily to drive the design process, providing the philosophy, examples, and contexts that inspired discussions. By May 2007, the committee had developed a framework for the course along with a proposed set of modularized topics based around several important issues in science.

\section{Course Teaching Team}

Selecting a course coordinator presented a substantial challenge, because the course crossed over traditional disciplinary boundaries. The idea of two coordinators, one from mathematics and one from the life sciences, emerged as a plausible solution. A professor of mathematics was chosen because he was experienced in teaching first-year mathematics students, had a proven record in both research and teaching (having won awards for both), had a track record of leading funded teaching projects, and was involved with the development committee for the course. A professor of parasitology was selected as the second coordinator. He had an outstanding record in both teaching and research and was recently awarded Australia's highest national tertiary teaching award. He had not been involved in the initial development of the course philosophy, so brought a new perspective to the course. A team-teaching approach was adopted with both faculty being present and actively involved in the delivery of every lecture. To complement the teaching philosophy adopted in lectures, the tutorials and computer practicals also were each team-taught by a tutor from mathematics and a tutor from science.

\section{Course Content}

To translate the committee framework into course materials, the mathematician consulted widely across differing disci-

Table 1. SCIE1000 course aims and objectives

\begin{tabular}{cc}
\hline \multicolumn{1}{c}{ Aims } & Objectives \\
\hline $\begin{array}{c}\text { This course aims to: } \\
\text { Introduce students to the interdisciplinary nature of } \\
\text { modern science; }\end{array}$ & $\begin{array}{c}\text { Students will be able to: } \\
\text { Analyze the interdisciplinary nature of modern science, including } \\
\text { some of the similarities and differences across a range of } \\
\text { discipline areas; } \\
\text { Instill an appreciation of the quantitative skills required for } \\
\text { the practice of modern science, regardless of discipline; } \\
\begin{array}{c}\text { Improve students' mathematical and computational skills in } \\
\text { the context of scientific problems and issues; and }\end{array}\end{array} \begin{array}{c}\text { Apply fundamental mathematical techniques that are important to } \\
\text { problems across a range of scientific discipline areas; } \\
\text { Involve students in analysis of some "big-picture" issues in } \\
\text { science. }\end{array}$ \\
$\begin{array}{c}\text { Explain key introductory concepts in computer science, design and } \\
\text { write simple computer programs in the language python, and } \\
\text { interprete the output of these programs; and } \\
\text { Communicate responses to quantitative and science-based problems } \\
\text { in a correct, logical, and scientifically appropriate style. }\end{array}$ \\
\hline
\end{tabular}


Table 2. Course content framework (Matthews et al., 2009)

\begin{tabular}{|c|c|c|}
\hline Real-world issue & Mathematical concepts & Scientific context \\
\hline Heart disease & Modeling (discrete vs. continuous) & Biology and physics: fluid flow, risk factors \\
\hline Media reporting & Quantitative reasoning and units & Scientific literacy \\
\hline \multirow{2}{*}{ Climate change } & Periodic functions & Geographical sciences and biology: daytimes and seasons \\
\hline & Exponentials and logarithms & $\begin{array}{l}\text { Biology and chemistry: algal blooms, radioactive decay, } \\
\text { pH scale }\end{array}$ \\
\hline Populations & $\begin{array}{l}\text { Discrete models, geometric models, matrix } \\
\text { models }\end{array}$ & $\begin{array}{l}\text { Microbiology, ecology, and psychology: bacterial growth, } \\
\text { stage-structured population models, behaviorism }\end{array}$ \\
\hline Drugs, sex, and depression & $\begin{array}{l}\text { Average rates of change, derivatives, Newton's } \\
\text { algorithm for finding roots }\end{array}$ & Pharmacology: pharmacokinetics \\
\hline Hypersonic flight & Antiderivatives and integration & Physics: motion \\
\hline
\end{tabular}

plines in science to match mathematical content with relevant science contexts. Using his experience of teaching first-year mathematics, his knowledge of the high school mathematics curriculum, and the recommendations of BIO2010, he was able to identify appropriate mathematical content and a reasonable sequence in which that material could be covered. He drafted a comprehensive "workbook" for the course, based around the identified mathematical topics, and then integrated the science context and identified real-world themes. He continuously worked with science colleagues to ensure the mathematical applications were relevant and appropriate, and used a number of upper-level math students to assist with development of content material for the course, mostly to edit and modify newly developed material. He used scientific research articles to inform the science he included. Once this was done, he brought the workbook back to the committee and the other coordinator for comment. Table 2 shows the course content framework, linking mathematical concepts with scientific contexts that were inspired by realworld issues.

Developing the programming content was also a substantial task. The course coordinator had taught programming courses in the past, and in addition a computer scientist was recruited to assist with developing appropriate content and tasks. BIO2010 stated that students should participate in a genuine programming experience, writing programs for themselves rather than running black box software. The language Python was chosen for this course, because it is a "real" programming language; is used in scientific research and by organizations such as NASA, YouTube, and Google; is easy to use; and is available for free download. A manual covering the core programming concepts also was developed for students. Areas covered include software design, good programming practice, variables and calculations, input and output, conditionals, loops, arrays, subroutines, and documentation.

\section{8: First Offering}

SCIE1000 was first offered in semester 1 of 2008. The lectures were highly interactive. For example, students solved context-based mathematical problems during classes and were encouraged to work with their peers. The lecturers would then encourage student questions and model how to solve the problems as required. The tutorials and computer practicals were structured around small-group learning, limited to 30 students per class. They were organized so that the same group of students would attend the tutorial first, followed immediately by the computer practical. The same two tutors would deliver both sessions, allowing students to work in cohesive groups and develop a relationship with each other and with the tutors over the 13 wk of the course.

A SCIE1000 workbook was provided as the primary resource for enrolled students. The workbook integrated numerous real-world examples, with short explanations linking mathematics to scientific disciplines, followed by problems requiring students to apply their mathematical thinking in context. Worksheets were developed for each tutorial and computer practical, and they provided students with an opportunity to further revise course content.

To allow for ongoing feedback and to scaffold student learning, the course assessment included five integrated assignments that were each worth $10 \%$. The assignments required students to apply mathematical thinking to solve a scientific problem, incorporating mathematics and programming in the context of various scientific subdisciplines. Elements of modeling underpinned all of the assignments. An example of an assignment question is provided in Supplemental Material 1. A comprehensive final exam worth 50\% was given after the completion of the course.

\section{9: Second Offering}

The second offering occurred in semester 1 of 2009. The course aims and learning objectives remained the same, but there were substantial changes to the course materials, course delivery, and assessment. The changes were informed by a comprehensive evaluation process, including a survey and a series of focus groups held in semester 2 of 2008. The need for substantial changes was not surprising given this was the first offering and that the general philosophy of the course was new. The course remained "highly recommended" for all commencing science students.

The workbook underwent substantial revisions before the second offering (see Supplemental Material 2). In October 2008, the first and second authors attended a Project Kalei- 
doscope (PKAL) Quantitative Reasoning (QR) Workshop ${ }^{1}$ that inspired the addition of a new section on QR and a new QR assessment task (described below). The emphasis on mathematical calculations was reduced and replaced with an increased emphasis on mathematical thinking and reasoning. The number of real-world examples was doubled, with most sections commencing with a genuine, real-world context to link more closely the application of mathematics to important science issues. The lecture component covering programming was expanded, a revised Python programming manual was developed, and the overall complexity of programming tasks was reduced (see Supplemental Material 3). The small-group learning experiences remained largely unchanged.

The course assessment also was revised. The number of integrated assignments was reduced from five to four. The amount of work required for each was reduced, and the overall weighting of the assignments was reduced to $30 \%$ of the student's final grade. A "big project" worth $20 \%$ was introduced, which represented a substantial piece of work linking concepts from science, mathematics, computer programming, problem solving, modeling, scientific communication, and critical thinking (see Supplemental Material 4). To better cater to the various areas of interest in science, students were given a choice of topics for this project. A pass / fail QR component also was integrated into the course, requiring all students to locate a recent media article that made quantitative claims. Students had to present the article and critique the quantitative claims during the tutorial. This assignment was inspired by the PKAL QR workshop. ${ }^{1}$ The exam was revised but was comparable in terms of content, length, format, and difficulty.

\section{Study Design}

This study was approved by the Human Ethics Committee at UQ. We collected data from students after completion of SCIE1000 in 2008 and 2009. Given the research questions and focus on student perceptions in this study, a survey approach was used to capture student self-reported data. A survey, based on the Student Assessment of Learning Gains, $^{2}$ was administered in the last 2 wk of the course in each offering. The survey incorporated the standard, generic university course evaluation questions along with several course-specific questions designed to gauge student perceptions. The survey was developed in partnership with survey design experts based in the central UQ teaching development unit and was administered solely through this unit (which was not associated with the course). The central unit collected identifying student information, although only deidentified, aggregate data were provided to the course teaching team. Students were made aware of this and asked to be as truthful as possible. In both instances, students were offered an incentive for completing the online survey, in the form of bonus points toward their final assignment, representing $<1 \%$ of the final assignment that was worth $10 \%$. The use of an incentive to encourage students to complete online surveys is common practice (Berk, 2006) and was not viewed by us as a factor causing bias in student responses.

\footnotetext{
${ }^{1}$ http://serc.carleton.edu/quirk/pkal_workshop08.

${ }^{2}$ www.salgsite.org.
}

\section{Study Participants and Response Rates}

SCIE1000 was highly recommended for all science-based bachelor students entering a science-based bachelor's degree at UQ in 2008 and 2009. The student demographic information between the $2 \mathrm{yr}$ is very similar in terms of gender, nationality, and age. University admission criteria did not change from 2008 to 2009; thus, academic abilities as indicated by admissions requirements also were similar across the two cohorts. Enrollments in the course were 569 and 491 in 2008 and 2009, respectively. The survey response rate for 2008 was $96 \%(n=$ $546)$ and in 2009 it was $87 \%(n=425)$. These response rates satisfy the confidence criteria for generalization to the larger population. A subpopulation of biology students was extracted from the data and analyzed for the purposes of this study. In $2008,68 \%(n=370)$ of respondents were biology students; in $2009,60 \%(n=253)$ were biology students.

\section{Data Analysis}

All Likert scale responses were assigned numerical values and analyzed in Excel (Microsoft, Redmond, WA). The survey contained different sections, which used either a 5-point Likert scale or a 3-point Likert scale. Descriptive statistics including mean and standard deviation are used to describe student perceptions. The magnitude of change from 2008 to 2009 was assessed using Cohen's $d$ effect size analysis. A value of 0.20 is considered a small effect, 0.50 is considered a medium effect, and 0.80 is a large effect (Cohen, 1992).

\section{RESULTS}

Figure 1 illustrates perceptions of biology students toward SCIE1000 overall, and their beliefs about the role of mathematics in biology. The figures highlight an improvement of 0.27 from 2008 to 2009 in regards to students' overall perceptions of the course. When asked about their perceptions of the importance of mathematics in biology, Figure 1 indicates very high levels of agreement, with a mean value of $4.05 \pm 0.74$ in 2008 and $4.49 \pm 0.32$ in 2009 .

The magnitude of change from 2008 to 2009 was calculated using effect size, indicating a small change (Cohen's $d=0.3$ ) in student perceptions of the course overall. How-

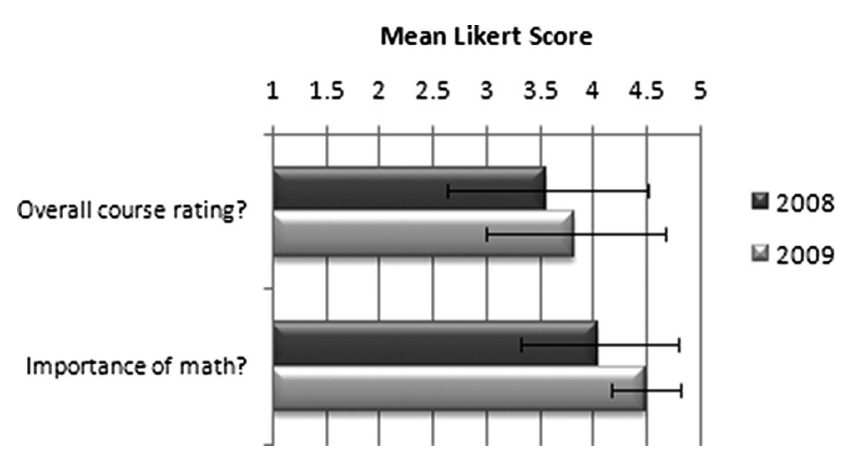

Figure 1. Biology student perceptions in 2008 and 2009 on a 5 -point Likert scale with standard deviation. The first survey question was, Think about your whole experience in this course. Overall, how would you rate this course? $(1=$ poor, $5=$ outstanding $)$. The second survey question was, How important do you think mathematics is in science? $(1=$ not at all important, $5=$ very important $)$. 


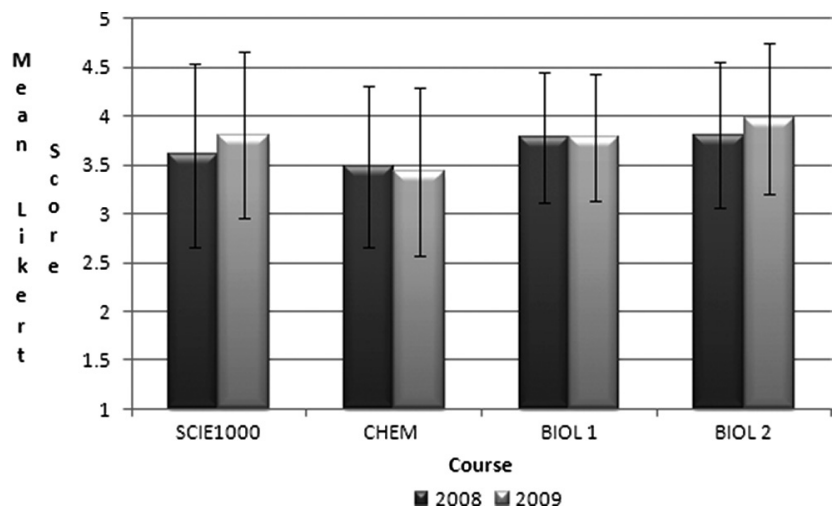

Figure 2. Overall rating for the four courses that make up the recommended first-year, first-semester curriculum for biology students, ranked on a 5-point Likert scale. The survey question was, Think about your whole experience in this course. Overall, how would you rate this course? $(1=$ poor, $5=$ outstanding). These results incorporate all respondents in all courses, not just biology majors.

ever, the change in perceptions of mathematics is more substantial, with Cohen's $d=0.67$.

These results show responses from only the biology students enrolled in SCIE1000. Student perception of UQ courses overall is gathered systematically through the standard course evaluation process. New science students interested in biology are encouraged to take four courses in their first semester of firstyear: SCIE1000, Chemistry (general chemistry), Biology 1 (introduction to cellular processes), and Biology 2 (biodiversity). Data on all students' perceptions of these courses are illustrated in Figure 2. In 2008, SCIE1000 was rated more favorably than Chemistry and less favorably than the two Biology courses. In 2009, SCIE1000 was viewed more favorably than Chemistry and Biology 1. Effect size (Cohen's d) from 2008 to 2009 indicates that SCIE1000 $(d=0.20)$ and Biology $2(d=0.22)$ showed similar positive changes. The magnitude of change in Chemistry $(d=-0.07)$ showed a slight decrease, and Biology $1(d=0)$ remained unchanged.

Student perceptions toward mathematics and programming as a result of taking SCIE1000 are displayed in Figure 3 , along with an indication of their intentions to take additional quantitative-based courses. The trend across both years shows that students are significantly more positive toward mathematics than programming. Although results for programming remain consistently low across both years, the mean value for mathematics increased by 0.34 from 2008 to 2009. Student intention to take more quantitative-based courses has a mean value of only $1.86 \pm 0.74$ in 2008 , with an increase of 0.17 in $2009-2.03 \pm 0.84$.

From 2008 to 2009, the effect size is largest for enthusiasm about mathematics (Cohen's $d=0.46$ ), with almost no difference for programming (Cohen's $d=0.02$ ). A small effect size is revealed for biology students' intentions to enroll in more quantitative-based courses (Cohen's $d=0.21$ ).

\section{DISCUSSION}

Analysis of the research questions and results of this study provide evidence to support the BIO2010 recommendations

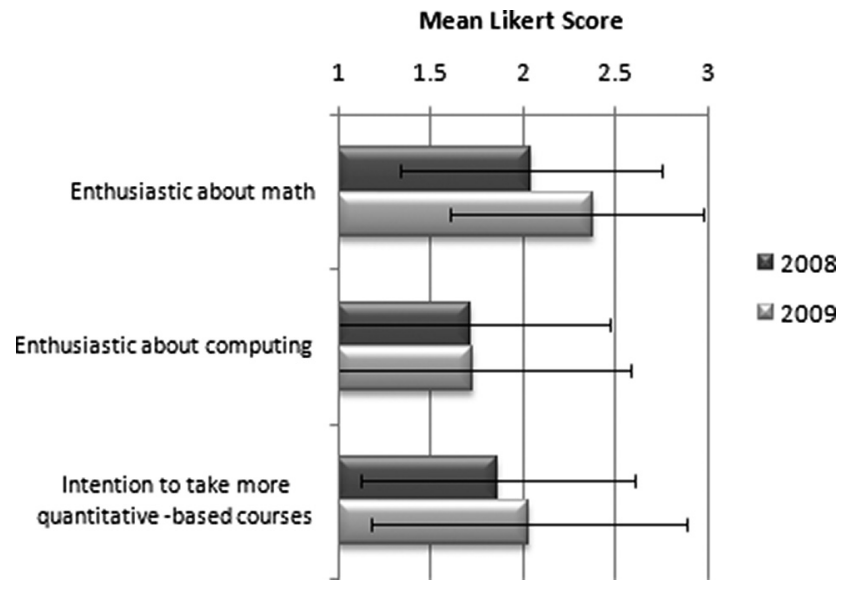

Figure 3. Biology student perceptions in 2008 and 2009 on a 3-point scale with standard deviation. The survey question was, As a result of participating in this course, rate the LEVEL to which you FEEL . . . 1 = low, $2=$ medium, $3=$ high).

that students should be introduced to the interdisciplinary and quantitative nature of modern science starting in first-year courses. Data show that biology students certainly can hold very positive perceptions toward the role and relevance of mathematics. However, the data also reveal that SCIE1000 did not result in the biology students developing any positive perception of programming and that students report low intentions of enrolling in additional quantitative-based courses.

\section{Research Question 1: Biology Students' Perceptions of an Interdisciplinary Quantitative Course}

SCIE1000 is a single course in a broader first-year curriculum composed of more traditional, single-discipline courses. There was substantial concern during the course development phase that students would not react at all positively to the course, given the fundamentally different nature of an interdisciplinary, quantitative course within a fairly traditional, single-disciplinary curriculum. Indeed, senior management in the Faculty of Science expressed a view that, if not implemented effectively, this course could "drive science students away from the University." These fears were unfounded: Evaluation of the first offering of SCIE1000 demonstrated that the philosophy of BIO2010 can be incorporated successfully in an introductory course. We view this as a powerful vindication of the broad recommendations of BIO2010.

After substantial changes to course content, student perceptions of SCIE1000 improved in the second offering. Not only did biology students respond more positively to the course, comparative ratings placed SCIE1000 slightly higher than a Biology course in 2009 (Figure 2). Although the standard deviation for the mean responses is greater in SCIE1000 than other courses, indicating greater variability among students, the overall mean rating of the course is comparable to the Biology courses and exceeds the Chemistry course in both years. Fears that students would reject the course based on the different nature of an interdisciplinary approach were not realized. The data also reveal no significant differences in course perception by biology stu- 
dents in comparison with the entire student cohort, in both 2008 and 2009 (Figures 1 and 2).

\section{Research Question 2: Biology Students' Perceptions of Mathematics and Programming}

Results demonstrated that students in the life sciences can hold positive perceptions toward the role of mathematics in biology as a result of a BIO2010-inspired course. Students reported high levels of agreement around the importance of, and their enthusiasm for, mathematics. The effect size from 2008 to 2009 demonstrates that the improvements in the course further enhanced student perceptions around the role of mathematics in biology. This finding is supported by previous research that has found teaching mathematics in context motivates students and enhances student attitudes (Elliott et al., 2001; Metz, 2008; Tariq, 2008; Pursell, 2009).

The role and impact of students' perceptions on their learning is important, and needs consideration when teaching biology students quantitative topics. Research in mathematics education has demonstrated the central role of student perceptions in learning mathematics (Schoenfeld, 1988; Leder et al., 2002). Although this is not explicitly referenced in $B I O 2010$, it is clear that the writers recognized the importance of changing perceptions as a means of improving undergraduate student performance in quantitative areas of biology. Previously published research by the authors has also found that student beliefs around the role of mathematics in science are well established by the time they reach university and have substantial implications for how quantitative topics are taught in first-year science (Matthews et al., 2009). Using real-world examples that demonstrate the authentic interdisciplinary nature of modern biology is a strategy for shifting perceptions.

Establishing positive perceptions of the role of programming in biology (in the manner suggested by BIO2010) was not supported by this study. The perceptions around programming did not change with inclusion of more authentic examples in the second offering, as occurred with mathematics. Unlike mathematics, few biology students enter university with any prior knowledge in the area of programming. After 2 yr of course implementation, the SCIE1000 teaching team has questioned the place of programming in the first-year biology curriculum. Research points toward the complexity and challenges associated with learning programming (Robins et al., 2003). In SCIE1000 and similar courses, students not only need to learn programming skills, but they also need to apply these to quantitative, real-world contexts. It is possible that this combination of demands proved to be too complex for students to be able to cope effectively.

The experience in both offerings of SCIE1000 suggests that the BIO2010 recommendation of embedding programming from first-year for biology undergraduates is both problematic and challenging and may even not be appropriate. In theory, covering programming starting in first-year courses sounds useful; however, translating this into practice proved difficult. The particular programming activities were carefully contextualized and linked into other course content, but feedback from students was largely very negative. More evidence on effective approaches for shifting perceptions of programming would be of substantial benefit to the sector. What worked for mathematics in SCIE1000 was certainly not effective for programming. However, this is perhaps not surprising: for $\approx 15 \mathrm{yr}$, introductory mainstream mathematics courses at UQ have included a component of MatLab programming. This component of the courses is invariably heavily criticized by students.

\section{Research Question 3: Biology Students' Intentions to Enroll in Additional Quantitative Courses}

Biology student intentions to enroll in additional quantitative courses is only partly realized, although a small change in effect size from 2008 to 2009 indicates that course improvements can influence this. BIO2010 may have overestimated the extent to which knowing that mathematics is important in biology would actually influence biology students to take additional quantitative courses. If upper-level quantitative courses are essential for life science majors, then undergraduate curricula may require more structure. The implications of this are substantial, requiring more (quantitative) biologists with the confidence to teach quantitative topics within their courses. It also would require even stronger collaboration between mathematics and biology departments, which is a challenge that few institutions have been able to address successfully.

\section{CONCLUSIONS}

Our focus in this article has been on a single course inspired by BIO2010, which forms a key component of a large curriculum change at UQ aimed at better preparing our graduates for the interdisciplinary, quantitative nature of modern science. SCIE1000 represents one strategy where faculty from mathematics, the biological sciences, and education came together to create, develop, implement and evaluate a truly interdisciplinary quantitative course for first-year students. This approach was chosen as a direct result of recommendations proposed in BIO2010. Despite some negative student perceptions of aspects of the course (particularly around programming), the course will continue to be offered and to be highly recommended for all science students. The programming component will be retained, rather than moving toward a more black box approach to computing, which would be counter to the recommendations of BIO2010.

Although we were eager to adopt an approach that directly linked mathematics and programming in the context of biology (as opposed to offering traditional mathematics and computer science courses), we believe that more changes are required. Currently, we are exploring complementary strategies to embed more quantitative topics in our first-year Biology courses. The 2010 American Association for the Advancement of Science ${ }^{3}$ report Vision and Change in Undergraduate Biology Education reiterates the BIO2010 call for action, and biology-driven projects are showing progress toward better embedding of mathematics and statistics in biology (Metz, 2008; Nelson et al., 2009).

BIO2010 was an influential, far-reaching report with ambitious goals as it was seeking to address a major, global issue in undergraduate science education. It was tremendously important in the B.Sc. curriculum review at UQ,

\footnotetext{
${ }^{3}$ www.visionandchange.org/VC_report.pdf.
} 
because it provided a high level of credibility and validation, and a target at which we could aim. The report validated issues facing undergraduate biology education in Australia, it inspired momentum around the redevelopment of the B.Sc. at UQ, and it offered suggestions that could be translated into practice. We believe that our B.Sc. is substantially better as a result. Given the complexities of the issues tackled in BIO2010, we believe that it will continue to have positive impacts far beyond 2010.

\section{ACKNOWLEDGMENTS}

We thank the writers of BIO2O10 and the National Research Council. This study was funded in part by the Australian Learning and Teaching Council (ALTC). Any opinions, findings, and conclusions or recommendations expressed are those of the authors and do not necessarily reflect the views of the ALTC.

\section{REFERENCES}

Becker, T., and Trowler, P. R. (2001). Academic Tribes and Territories: Intellectual Enquiry and the Culture of Disciplines, Philadelphia, PA: Open University Press.

Berk, R. A. (2006). Thirteen Strategies to Measure College Teaching, Sterling, VA: Stylus.

Bialek, W., and Botstein, D. (2004). Introductory science and mathematics education for 21st-century biologists. Science 303, 788-790.

Burns, M. (1998). Math: Facing an American Phobia, Sausalito, CA: Math Solutions Publications.

Cohen, J. (1992). A power primer. Psychol. Bull. 112, 155-159.

Elliott, B., Oty, K., McArthur, J., and Clark, B. (2001). The effect of an interdisciplinary algebra/science course on students' problem solving skills, critical thinking skills and attitudes towards mathematics. Int. J. Math. Educ. Sci. Tech. 32, 811-816.

Gross, L., Brent, R., and Hoy, R. (2004). The interface of mathematics and biology. Cell Biol. Educ. 3, 85-92.

Kennedy, D., and Gentile, J. (2003). Is Bio2010 the right blueprint for the biology of the future? Cell Biol. Educ. 2, 224-227.

Leder, G., Pehkonen, E., and, Törner, G. (eds.) (2002). Beliefs: A Hidden Variable in Mathematics Education?, Dordrecht, The Netherlands: Kluwer.
Matthews, K. E., Adams, P., and Goos, M. (2009). Putting it into perspective: mathematics in the undergraduate science curriculum. Int. J. Math. Educ. Sci. Tech. 40, 891-902.

Marsh, J. F., and Anderson, N. D. (1989). An assessment of the quantitative skills of students taking introductory college biology courses. J. Res. Sci. Teach. 26, 757-769.

May, R. (2004). Uses and abuses of mathematics in biology. Science 303, 790-793.

Metz, A. M. (2008). Teaching statistics in biology: using inquirybased learning to strengthen understanding of statistical analysis in biology laboratory courses. CBE Life Sci. Educ. 7, 317.

National Research Council (2003). BIO2010: Transforming Undergraduate Education for Future Research Biologists, National Academies Press: Washington, DC.

Nelson, K., Marbach-Ad, G., Schneider, K., Thompson, K., Shields, P., and Fagan, W. (2009). MathBench biology modules: web-based math for all biology undergraduates. J. Coll. Sci. Teach. 38, 6 .

Onwuegbuzie, A. J., DaRos, J., and Ryan, J. (1997). The components of statistics anxiety: a phenomenological study. Focus Learn. Probl. Math. 19, 11-35.

Pan, W., and Tang, M. (2005). Students' perceptions on factors of statistics anxiety and instructional strategies. J. Instr. Psychol. 32, 205-214.

Pursell, D. (2009). Enhancing interdisciplinary, mathematics, and physical science in an undergraduate life science program through physical chemistry. CBE Life Sci. Educ. 8, 15-28.

Robins, A., Rountree, J., and Rountree, N. (2003). Learning and teaching programming: a review and discussion. Comp. Sci. Educ. 13, 137-172.

Schoenfeld, A. H. (1985). Mathematical Problem Solving, Orlando, FL: Academic Press.

Schoenfeld, A. H. (1988). When good teaching leads to bad results: the disasters of 'well-taught' mathematics courses. Educ. Psychol. $23,145-166$.

Slonczewski, J., and Marusak, R. (2004). A response to BIO2010, transforming undergraduate education for future research biologists, from the perspective of the biochemistry and molecular biology major program at Kenyon College. Biochem. Mol. Biol. Educ. $32,151-155$.

Steitz, J. (2003). BIO2010-New challenges for biology educators. Cell Biol. Educ. 2, 87-91.

Tariq, V. (2008). Defining the problem: mathematical errors and misconceptions exhibited by first-year bioscience undergraduates. Int. J. Math. Educ. Sci. Tech. 39, 889-904. 